\title{
Collaborative App-Making as a Community Engagement Research Method
}

Samuel Gerald Collins, Matthew DuRington, CANDACe EVerette, JamyA

ANDERSON, KIRTSEN FOSECA, JAKAYLA HOLMES AND CA'SYAH WATKINS

\section{ABSTRACT}

This article details an ethnographic community engagement project involving mobile app technology as a participatory methodology to create a walking tour of a Baltimore neighborhood. Greenmount West is an historically African American community in Baltimore City that is now experiencing rapid gentrification. After receiving a "mash up" grant from a local museum, researchers from Towson University were partnered with the director of a local community center in the Greenmount West neighborhood and collaboratively crafted the idea to create a walking tour through the perspective of youth.

In this case, four Black young women who were already involved in activities at the community center were solicited to participate in the ethnographic research and mobile app development project. Through a community engagement process that matched traditional ethnographic methods and technological development as

Authors

SAMUEL GERALD COLLINS

Towson University

MATTHEW DURINGTON

Towson University

CANDACE EVERETTE JAMYA ANDERSON KIRTSEN FOSECA JAKAYLA HOLMES CA'SYAH WATKINS Greenmount West Community Center methods, they shared their perspectives on their changing neighborhood and were involved in every facet of producing the tour. The goal was to put the agency and perspective of these young women as the leading voice of this process and development of a mobile app walking tour.

The article provides a step-by-step process for how to use this particular technology as a form of community engagement and research.

Keywords: Mobile Apps, Gentrification, Community Engagement, Technology, Ethnography 


\section{INTRODUCTION}

In cultural anthropology, and one could argue in society at large, the smartphone is now an indispensable tool. Over the last several years through a process we refer to as "Networked Anthropology" we have experimented and conceptualized ways to use technology as a methodological tool in ethnographic research. We define this approach as, "An anthropology undertaken in the age of multimedia social networks, one in which all of the stakeholders ethnographers, interlocutors, community, audience - are all networked together in various (albeit powerful and unequal) ways" (Collins and Durington, 2015, pp. 4-5). Through this approach we have developed ideas on how to utilize various technologies such as mobile apps as a way to not only explore communities but also as a means of producing material relevant to ethnographic research (Collins et al., 2017).

From keeping in contact with collaborators, to recording interviews, making photographs and film, and "live field noting" 1 the ethnographic process $^{2}$, anthropology has become app-driven: the smartphone has supplanted the ethnographer's paper notebook. That said, the process is not without controversy, and questions over the ethics of app-based media continue to arise--as well they should. Many apps are, after all, for-profit platforms that are (on many levels) monetizing the work of anthropology for profits that neither the anthropologists nor the communities in which they work will enjoy. Yet, we make the assertion that any community engagement activity in the $21^{\text {st }}$ century is relying upon this technology as well, whether one is conscious of it or not. Therefore, this conceptual project informed by and producing ethnographic

1 Taking field notes is one of the primary methodologies in cultural anthropology. When conducting ethnographic research an anthropologist will listen intensively to collaborators while conducting participant-observation (both participating in and observing cultural interactions) and will later reflect on this experience and record postevent field notes as records. "Live" field noting connotes the process of doing this in real time as events are
For many of us, the collaboration needs to come first, and, moreover, arise from people in the community. In other words, only when people articulate their need for our collaboration do we begin the research process.

research challenges community engagement practitioners to consider the role technology should inform their methods and findings.

There are many concerns about using technology in ethnographic research and while there is a comfort level with most audio-visual technologies, researchers have been slow to incorporate other networking and social media technologies in their work in a meaningful way. The same concerns are also present in the general public, whose digital labor -- the liking, sharing and following actions of individuals on mobile apps -- create a product for app developers and social media platforms to develop algorithms and targeted advertising. Essentially, our work as anthropologists and the browsing of our collaborators is a product that becomes monetized and sold back to us through mobile apps and social media. At the same time, we have simultaneously noted that the journal articles and books that anthropologists publish are hardly profit-sharing endeavors in and of themselves. The paywalls academic journals erect are obstacles to access for many of the communities in which anthropologists work, an obstacle that this journal thankfully works against. Smartphone-based apps, on the other hand, are accessible and familiar to both anthropologists and our community collaborators. For example, we all can show pictures and videos to friends and family, and people can discuss

occurring. While one can use tools such as pen and notepad for this, the smartphone offers up another tool to not only jot down notes in a writing application, but also record video, sound and take photos.

2 Ethnography is the primary methodology of cultural anthropology which utilizes fieldwork and participant observation to study cultures while being immersive in those environments over an extended amount of time. 


\section{Figure 1}

The landing page for the Greenmount West mapping project.

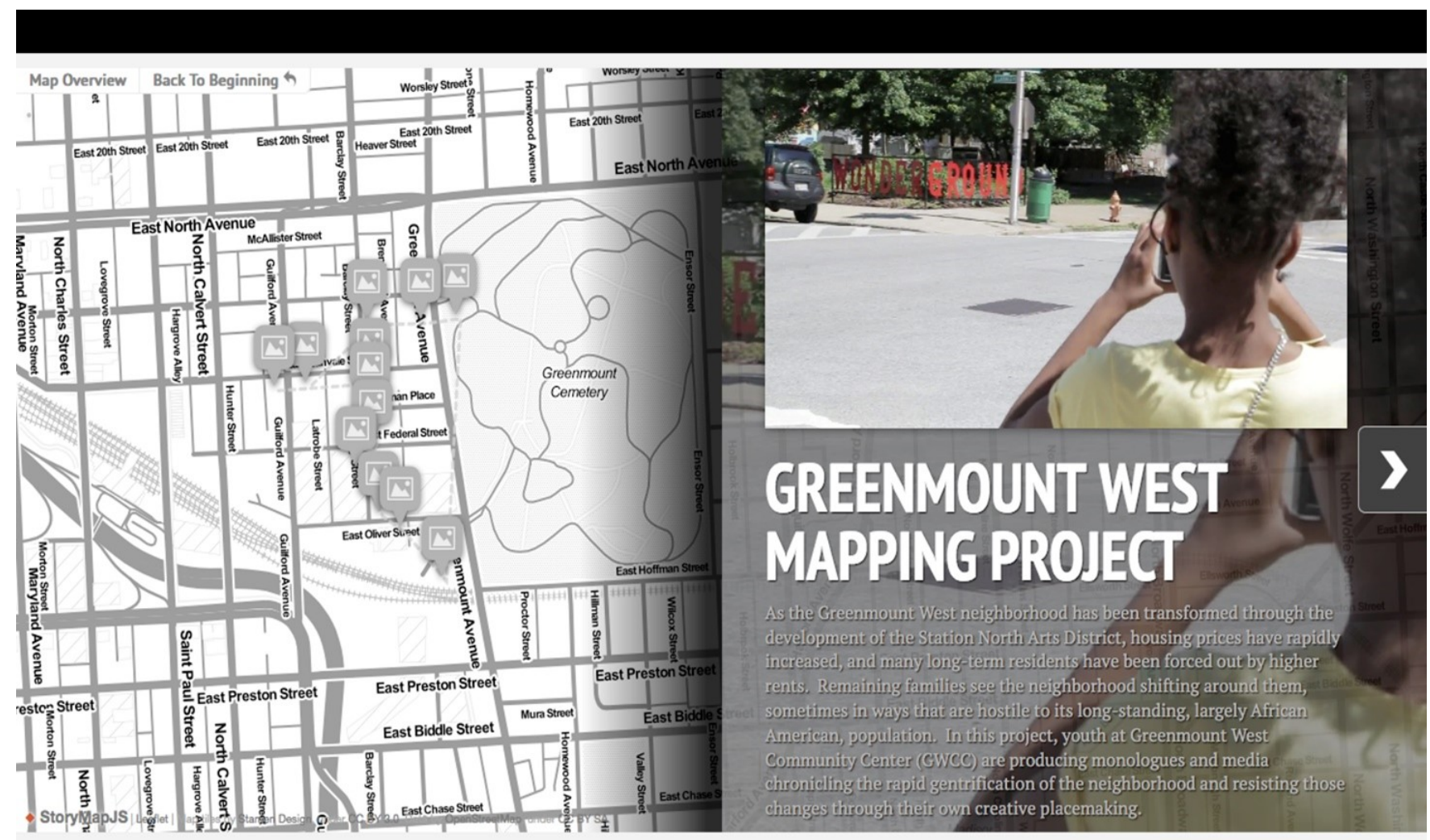

results accessible online much more readily than essay publications in obscure journals. Our assertion is that the smartphone can help drive an ethnographic project with the goal of creating a collaborative mobile app development to produce an outcome accessible to all parties.

This essay outlines an ethnographic project that produces a collaborative, app-building exercise in Baltimore, MD, involving anthropologists (Collins and Durington), the Program Manager of Greenmount West Community Center (Everette) and young residents of the neighborhood (Anderson, Foseca, Holmes and Watkins). Over the course of several weeks in the summer of 2019, we created and published an app-based walking tour of the Greenmount West neighborhood from the perspective of its young residents aged 9-12 years old. Our young collaborators were already involved in after school projects at the Greenmount West Community Center and when presented with the opportunity to participate agreed to do so with the consent of their parents and guardians. As researchers, we were pleasantly surprised by the tenacity and initiative shown by our young collaborators as they intensively discussed their neighborhood, engaged in mapping exercises and guided our walks throughout the neighborhood as we developed the tour. We also knew that our young collaborators had a keen sense that the neighborhood was changing and were already familiar with the term "gentrification" having heard it discussed by many around them. They also shared with us throughout the process the possibility that they may be losing their favorite places or might have to even move and leave their friends due to changes in the neighborhood. 


\section{Figure 2}

The izi.travel website for the Greenmount West walking tour. https://izi.travel/en/88aagreenmount-west-community/en

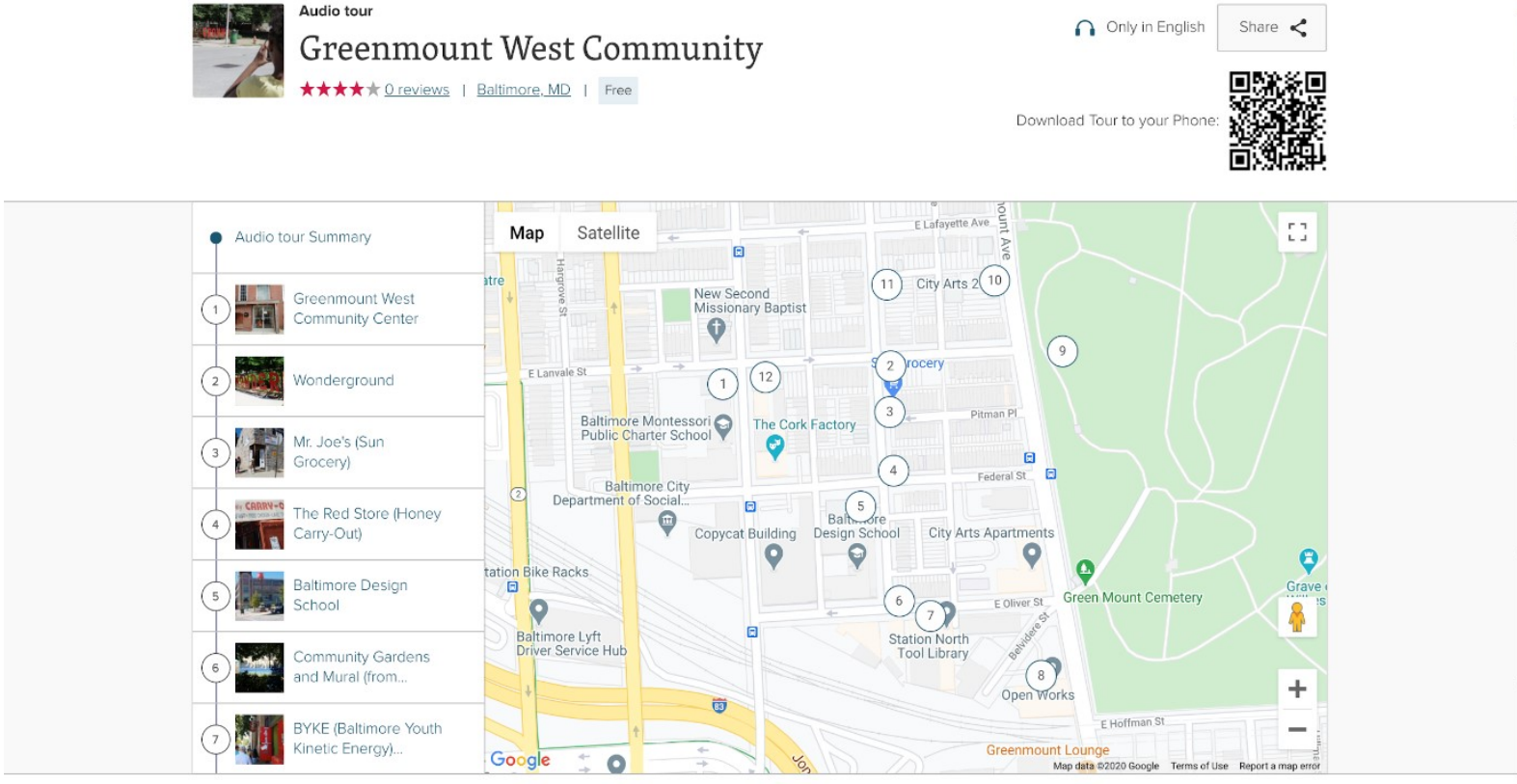

Gentrification has occurred in Baltimore just like many other cities throughout the United States in a process undergirded by discriminatory historic processes such as redlining that depreciated urban neighborhoods in the latter 20th century (Durington et al 2009). Gentrification relies upon the stereotyping of racialized urban neighborhoods as riddled with crime, drugs and other social pathologies making them ripe for possible change by developers, politicians and others as potential investments for redevelopment. These neighborhoods and communities tend to have little home ownership and high rental occupancy and thus become attractive for redevelopment that caters to new, often mostly white, residents who move while historic, often Black, residents are displaced. This same process has occurred in dozens of historic Black neighborhoods throughout the United States and in Baltimore.

\footnotetext{
${ }^{3}$ https://bniajfi.org/community/Clifton-Berea/
}

Greenmount West is an historic African American neighborhood adjacent to the west downtown core of the city of Baltimore. The larger demographic profile of the community in which Greenmount West is located is $93 \%$ Black, with a median household income of $\$ 31,219$, and $50.1 \%$ of children living below the poverty line. An indicator of incoming change is a rising racial diversity index of $17 \%$ with Whites making up $2.4 \%$ of the total population as of $2018 .^{3}$

Gentrification in the Greenmount West neighborhood was inevitable with the changing development patterns of Baltimore, but it was triggered through the designation of a nearby newly labeled arts district by the city which is often just one signal of impending gentrification. When this occurs, housing prices rapidly increase, and many long-term residents are then forced out by higher rents. Those remaining families see the neighborhood shifting around them, sometimes in ways that are hostile to its long-standing, largely 
Black population. This project's goals were therefore two-fold: to document a neighborhood undergoing rapid change through gentrification, and to help neighborhood youth engage in placemaking in a neighborhood changing before their eyes, in often unwelcoming ways.

\section{SMARTPHONES AND APPS AS A RESEARCH TOOL}

As smartphone access has increased globally, apps have become an everyday part of life for many people in the world. The ubiquity of apps demands that researchers pay attention to them as a medium of communication and as cultural media in their own right. Apps are global and utilized everywhere throughout the world. One only has to survey a classroom to find dozens of apps that students use on a daily basis to post content on social media, navigate their surroundings through GIS mapping or connect with others around them in unique ways. In South Korea, for example, nearly 100 percent of the population uses Kakaotalk (a messaging app with video capabilities) (Hjorth 2014). It would be difficult to do any research in South Korea without Kakaotalk -- it has become literally the platform upon which social life is built. Beyond this particular example, it is easy to assert that apps are a global phenomenon. In other words, not only should researchers be studying life in the context of these apps, but the apps themselves function as indispensable field working tools. If a researcher is not gauging what mobile apps their collaborators are using in their everyday lives, then they are truly missing a major part of the culture they are studying. While we still need to be critical of these new media, as Kenner (2016) has pointed out in her study of the neoliberal underpinnings of asthma apps, we no longer have the luxury of simply ignoring them as ancillary to either our scholarly work or our work in community engagement.

Besides, apps offer researchers distinct affordances in their work in urban communities. First, apps are mobile, and, as such, they mirror
Fundamentally, community engagement work and research must always start with the perspectives of the local populations we interact with. And, simultaneously, there should be an ethical concern to create a constant mechanism for feedback and involvement. Hence, we do not adhere to the hierarchical authorship of the academics being the sole authors, but positioning our interlocutors in the same space.

the mobility of communities themselves: the daily travels that bring people across their neighborhoods, through the city, and back again. Second, apps support multimedia. Unlike conventional media, divided up into print and visual media, apps evoke transmedia possibilities that mirror the way we counter media in daily life. Finally, apps accessed through smartphones present sensory experiences -- we often only know where to walk with a phone app, which is operated according to technology interfaces built into the app such as GPS tracking. With all of the multimedia contained in them, apps suggest a better way of engaging the senses in our research through what Sarah Pink calls "sensory ethnography” (Pink, 2009). Sensory ethnography encompasses multiple senses gleaned from walking, feeling, hearing and seeing. Thus, apps extend the possibility of higher forms of community engagement, experiencing and, ultimately, involvement. In this way, we have suggested that apps represent the future of the discipline of anthropology and ethnographic research (Durington and Collins 2016). Now is the time for practitioners of community engagement from any disciplinary background to recognize that the capacities of these technologies should not be ignored but actively utilized and theorized.

\section{RESEARCH ETHICS AND DESIGN}

We adhere to an ethical obligation to collaborate and reciprocate in our research as cultural 


\section{Figure 3}

The research team prepares for a transect walk in the community.

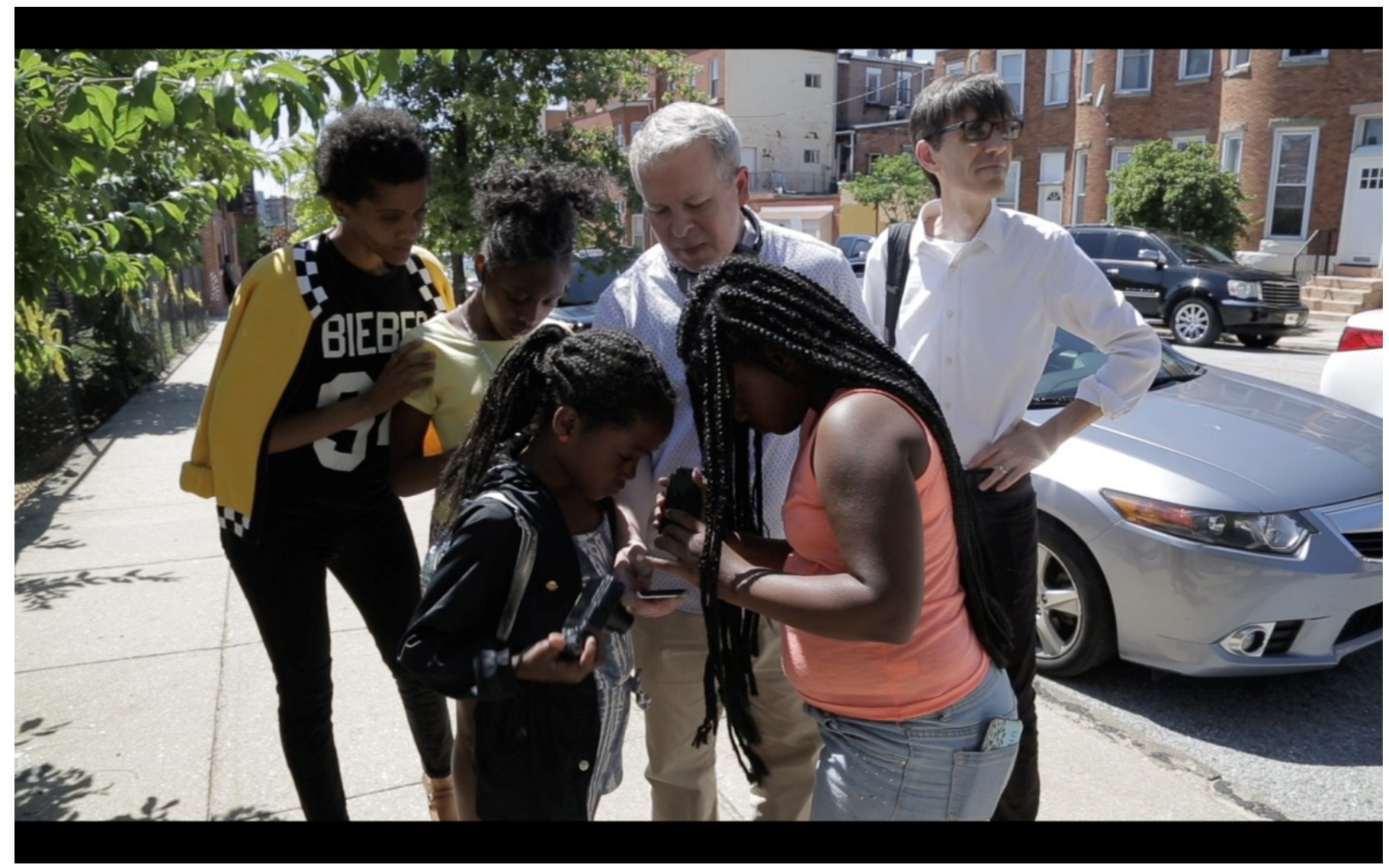

anthropologists. Many of us collaborate with people in the communities where we work. This, after all, is part of the applied and public research that characterizes much of the work in community engagement writ large. Of course, the meaning of collaboration varies across context and discipline. In anthropology, collaboration has meant researchers striving to incorporate the voices and the perspectives of the people with whom we work in the research we produce. For many of us, the collaboration needs to come first, and, moreover, arise from people in the community. In other words, only when people articulate their need for our collaboration do we begin the research process. The same ethos should guide any community engagement exercise and anthropology, among other social sciences, provides those parameters and methodologies.
While there may be some trepidation to use technologies such as mobile apps and others, to ignore their omniscience in culture would be a shortcoming.

This particular project grew out of an intermediary, the Peale Museum in Baltimore, that supports and displays storytelling projects from around the city. They had offered a "mashup" grant program, where teams would pair up to produce original work together, and Collins and Durington had fortuitously proposed a very similar project to Everette and the West Greenmount Community Center. Both of the proposed projects involved documenting the changing face of the Greenmount West community. Everette proposed working with children at the Center; they were extremely conscious of the changing politics of the 


\section{Figure 4}

Taking pictures of an important site on the walking tour for the online platform.

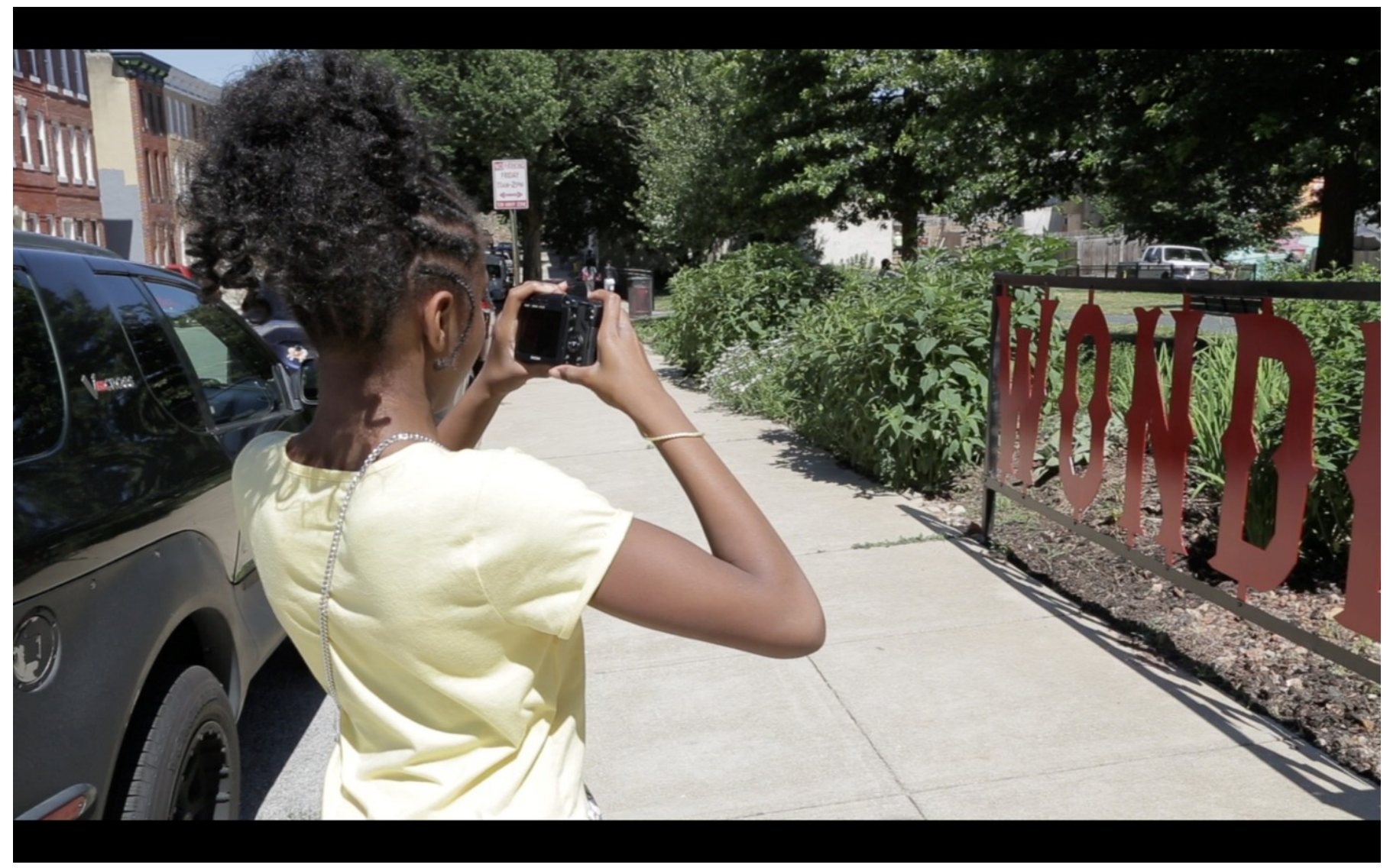

neighborhood, and the ways that processes of gentrification were infringing on their own sense of place through both enclosure and through increased rents that were literally pushing longterm residents out of the neighborhood altogether, including some of the youth and their families that we were working with. We all agreed collaboratively in rapport building sessions that the goal of the project would be to help the children articulate their stories of the neighborhood, and the eventual forms this would take included mixed media -- performance, an art installation and an app.

Design and implementation begins with rapport building and forming a community of practice. Initially in this dialogue, community members may express their desire to develop a new app to introduce their communities and their projects.
Geolocated apps allow a community to represent their neighborhood at a very material level: to people walking its streets. While this is certainly attractive as a platform, app development is an expensive proposition. Moreover, many of the functions that community groups may desire require extensive work on the back end, in the form of a substantial database housed on a server. One solution to this is to prototype specific app functions with the community in order to "triage" their relevance to community needs. In other words, after ascertaining what our collaborators want to do, we attempt to find platforms and ways to utilize technology to meet these interests. After this process, community members can revisit the question of app development with a better sense of what might work for their community. 


\section{Figure 5}

The picture taken in Figure 4 in the StoryMapJS tool with contextual quotes from our collaborators and co-authors.

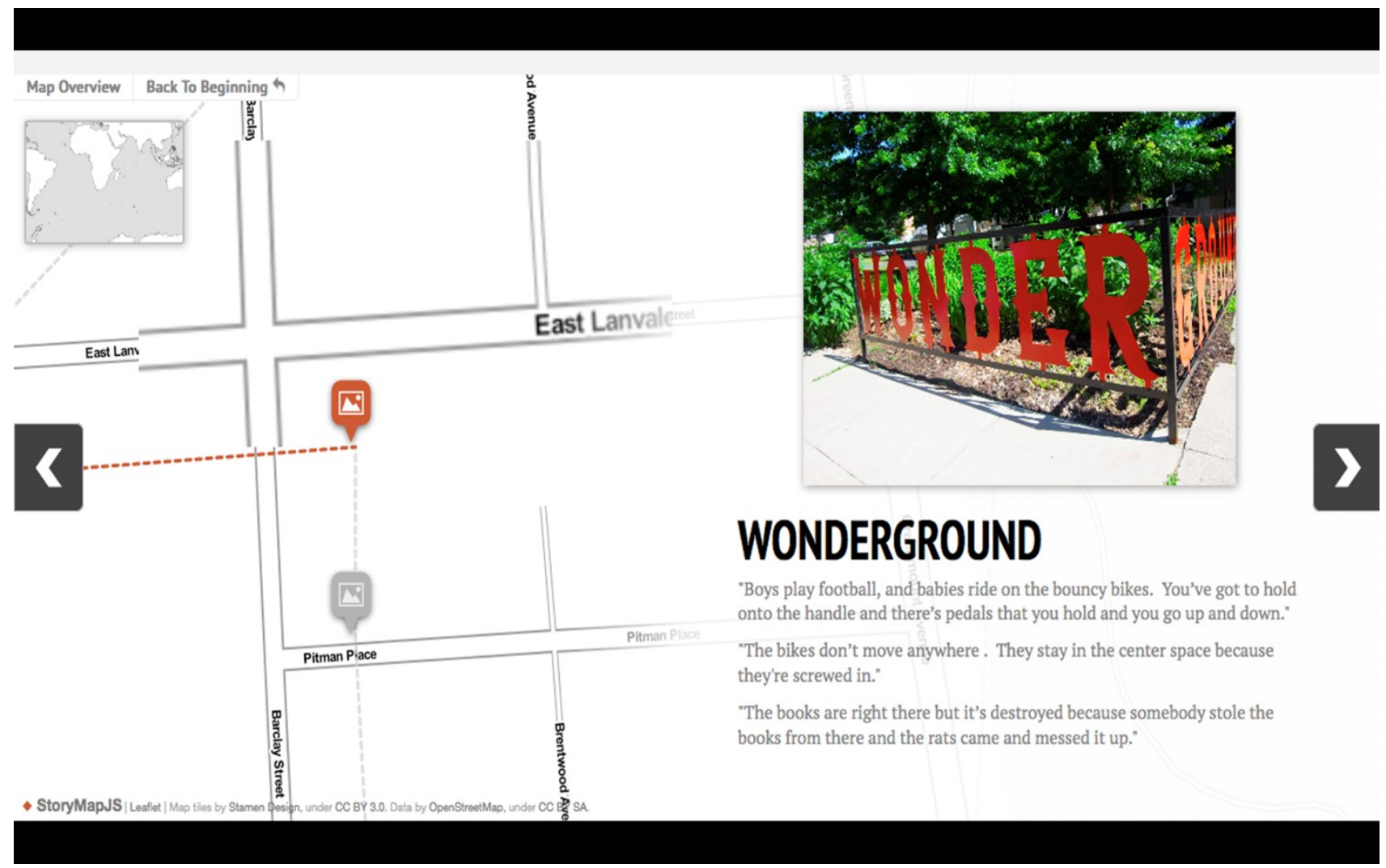

There are many app platforms out there that can be used for community projects like these. Many can be re-purposed in order to serve politically committed needs. Of course, many of these app platforms may be initially free, but require monthly fees in order to maintain and advertise the app. An exciting development in recent years is the proliferation of open source and open access platforms that remain accessible without monetization. After considering multiple app platforms, we decided on a free tour app platform called "izi.TRAVEL." The platform supports the development of geolocated tours, multimedia tours, and includes possibilities for text, audio, photography and hyperlinked media. As of the writing of this essay, the app remains free, although there are now pop-up ads on the smartphone app (that, of course, can be removed through paying a fee). More importantly, there are no fees for uploading multimedia content to the platforms despite the size of data. Since several universities and non-profits have created tours hosted on izi.TRAVEL, there are an especially rich and varied collection of "tours" available for Baltimore. Many of them are examples of "creative misuse" (Farman, 2016), a process whereby one utilizes technology for a purpose it was not designed for, such as utilizing a travel platform to spotlight social problems and structural inequalities in a city rather than tourist attractions.

Of course, there is always the option of developing different apps or migrating to a fee-based platform. Whatever platform people choose, the important point is that the data should exceed the platform: collaborators should generate more interviews, more video, audio and mapping than they need for their app. And it is helpful to be 
redundant. For example, a walking tour developed on this platform can be easily replicated on other web platforms that serve as a quasi-archive. It may be that this excess data ends up on an online archive for others to peruse, as Durington and Collins did with their "Anthropology by the Wire" project (http://anthropologybythewire.com)

Despite its recent tumultuous activity, we have found the Tumblr platform useful for this purpose. But whatever the case, collaborators need to have as rich and varied a data set as possible, if for nothing else, to support multiple forms of dissemination that might result in the future of being used in other media-based community engagement projects with collaborators. And, with digital photography and media technologies being readily available on the average smartphone, the tools are there at hand and collaborators already possess a level of proficiency. One only has to glance at Instagram to realize the huge amount of photography posted by youth populations, even if they are mostly selfies.

What follows are steps in the methodology that utilizes technology for participatory ethnographic research that we have developed and implemented in this project. While there is a focus on developing and utilizing technology, there is a simultaneous opportunity to glean valuable ethnographic information throughout the participatory process. The development of a collaborative mobile app walking tour includes multiple conversations, social mapping, participant observation, background research and media analysis and production. All of these are hallmarks of ethnographic research, therefore the assertion is that the mobile app development is the end to an ethnographic means.

\section{Methodology I: Community and Technology Assessment}

It is important for the reader to understand that while the description of the mobile app

\footnotetext{
${ }^{4}$ Participatory Action Research (PAR) seeks to utilize research between community members and researchers to
}

\section{It is the editorial control given to the people you are working with that empowers their voices as experts in the community and creators of its representation.}

production methodology focuses on showing the reader how to do this, it should also be realized that this process is not done by automatons working in silos. It should be taken as a given that as we work collaboratively; we are discussing a variety of things such as background stories, observations about the community, likes and dislikes and other everyday things that most technology developers might dismiss, but ethnographers value as data. As our youthful collaborators were being taught about the development of a mobile app walking tour, they were providing us ethnographic insight into their daily lives, their families and their communities. Therefore, we recommend that community engagement practitioners wear two hats simultaneously: experiment with these technology methods, but remember that ethnographic insight undergirds the process and the dual data produced by the process, both technological and cultural.

The first step in this process is to decide which features of the community to highlight. Here, we take our prompts from participatory action research ${ }^{4}$ and, in particular, the experiences of photovoice researchers (Gubrium and Harper, 2013). Photovoice is a methodology that empowers communities to represent themselves through collaborative, visual forms such as photography that is frequently exhibited in schools, galleries, coffee shops and other significant places in communities. The idea is that communities represent their daily lives, and then there are convening events where dialogue is

develop information for direct change through collective inquiry. 


\section{Figure 6}

Recording descriptive audio for the walking tour.

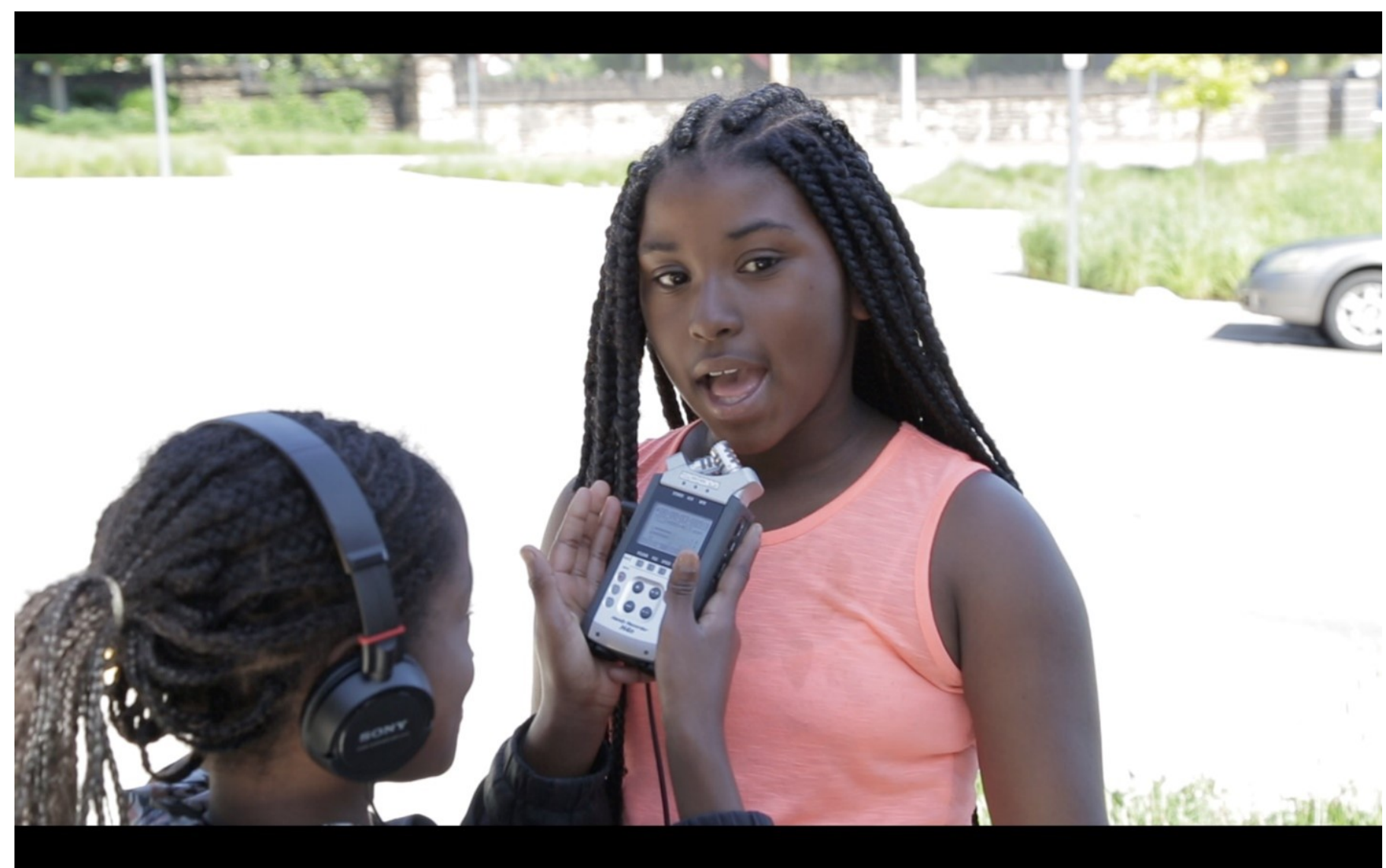

fostered between community members and others. In June of 2019, Collins, Durington, Everette and children from the Greenmount West Community Center met to map their neighborhood through an examination of the "daily round ${ }^{5}$." Associated with the work of Eliot Liebow, Ulf Hannerz and others, "daily round" methods emphasize the neighborhood as a source of rich social connection and reciprocity, and as a method is an important corrective to overemphasis on family and employment as the only salient sites for social observation. This honed method from social science helps push back against murky uses of reciprocity as a community engagement strategy. As Dostilio et al. states, "Understandings and applications of the concept

${ }^{5} \mathrm{~A}$ focus on the "daily round" gives meaning to the daily walks to and from locations such as school, neighbors' of reciprocity may vary widely, distinctions among uses of the term may be overlooked, and this term may be easily conflated with others" (Dostilio et al., 2012).

By thinking critically about the hierarchical nature of community engagement work we seek to empower our community collaborators to safeguard issues that can occur despite possessing a participatory and reciprocity ethos. This is particularly important in a place like Baltimore where youth are not only racialized but often not provided a voice or platform to talk about their communities. By providing a space and a platform for their voices, our young collaborators are positioned as those possessing local knowledge

houses, stores, work and others and the social encounters and observations one has during those times. 
and educating academic outsiders about their communities and lives demonstrating true reciprocity. And the fact that we are positioning our interlocutors as co-authors of this piece and not simply as research participants demonstrates a disruption of hierarchy in participatory work and authorship that all community engagement practitioners should employ.

\section{Methodology II: Media and Documentation}

Having identified numerous sites, the collaborators agreed on some good days and times for "transect walks" through the community that would capture all of the sites the children had identified. Of course, the point was to not only identify those sites, but to explore their significance and the sense of belonging that came with the children's place-making. Accordingly, the team brought multiple technologies with them -- cameras, digital recorders, and video cameras. Over a three-hour session, the group created an overlapping media archive. While we benefit from having access to these different technologies, it is important to assert that this could be done with the average smartphone as well. The capturing of media on these transect walks is collaborative as well. While we are shooting footage of the children talking to create a primary editing roll, we employ other cameras simultaneously and also put these cameras in the hands of our collaborators. This footage is spliced in and often possesses on-thespot interviews of our collaborators interviewing each other in addition to describing sites important to them on the daily round. As the process unfolds, we have seen time and time again that the more you provide the means of representation to your interlocutors, the collaboration becomes more powerful and our partners begin to take more control of the process of representation in community engagement.

After creating the video, still photography and audio footage, we utilize editing software such as Adobe Premiere and Audacity to edit video and audio into clips. We also utilize Adobe photoshop for still photography. This edited cache of

\footnotetext{
${ }^{6}$ A "transect walk" is different than a "daily round" in that you determine a specific route to walk with community members' input and then observe resources, landscape
}

multimedia is then given back to our collaborators for assessment and possible inclusion in the mobile app walking tour or any other means they might need it for. This latter step is crucial in that the community members must be positioned as the primary editors. We simply provide the fodder for them to utilize in collaboration. (We can promise the reader that this particular set of collaborators had no problem telling us what they didn't like.) This method tends to take the labor off of our collaborators and is useful for rapid projects, but there are other methods that utilize longer amounts of time to work with and tutor interlocutors through these technologies. Although it may be redundant, it is important to stress once more that all of these editorial processes can be found on free platforms and in apps on smartphones. Our savvy collaborators also had the capacity to edit media as it was loaded on to the izi.travel platform to build out the mobile app walking tour. This process of collaborative media creation once again positions our partners as both the educators about the community where they live, and also ensures that the now created media representations are vetted and approved before being disseminated on a public platform.

\section{Methodology III: Prototyping Technology}

Even after collaborators have a sense of the sites, there's still a real question about what kind of app to build. With a tour app, the questions also include: where do you want people to go, and how do you want them to get there? The first step in any app design is to create a model of the tour that captures the flow of sites across the map. In the past, Durington and Collins have used pencil and paper or prototyping applications like "Prototyping on Paper" (POP), which allows users to hyperlink their pen-and-ink drawings in order to simulate the flow of an app. In either case, the point of the exercise is to think about the user experience. This app is about walking. But how should people walk? In what order should they see significant sites? And how? What kinds of explanatory context should accompany images

and other features to prompt explanations of what meaning those observations have to community residents. 


\section{Figure 7}

One of the stops on the walking tour is referred to as "The Red Store" by youth in the community despite its actual name. As the ethnographic quote illustrates it may be problematic, but it does have "icys."

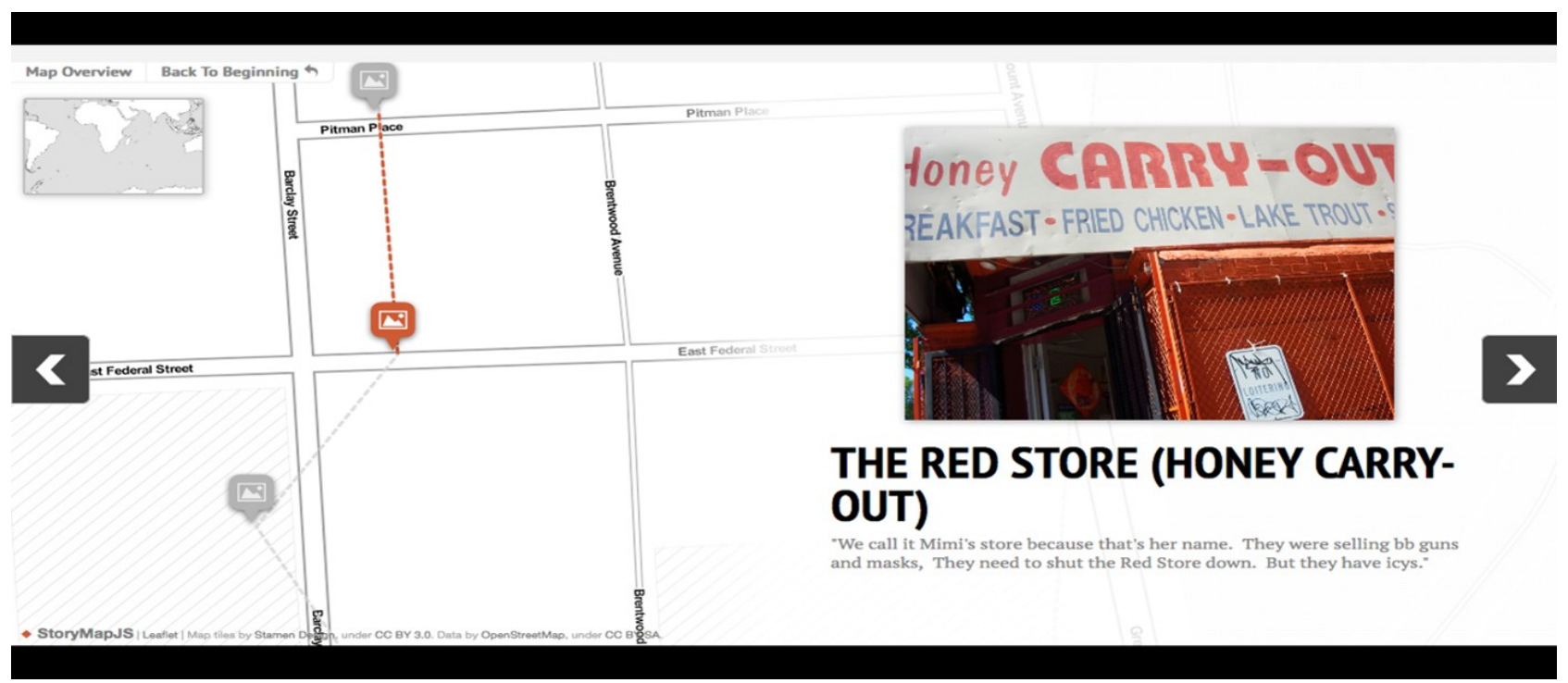

and audio? And how detailed should these be? And are they narrated by our collaborators? Many features in a community may require sophisticated contexts and some features associated with gentrification may be welcomed by a community that has historically experienced under-investment. But there are also tensions and to see those through the lens of youth in the community provides a rare perspective.

For the prototyping phase of our project, we utilized a mapping tool, Knight Lab’s "StoryMap," a free application that allows people to visualize their daily round with text and photographs.

These entries were completed with the children from the Community Center and became the basis for mapping out the narratives for the app, as well as selecting media. Laying out the prototype also showed us the holes in our work: where we needed more photographs or where there were more questions that needed to be answered.

\section{Methodology IV: Editing}

Once entries are complete, we undertake an editing process that involves conversations with our collaborators about what is working and not working. Using the same software noted above (Adobe Premiere, Audacity, Adobe Photoshop) we then complete another round of editing to "clean up" the footage and find additional footage, pictures or audio to fill the identified holes in the narrative being created. While capturing media is often seen as the primary component of this type of participatory fieldwork, we would assert that the editorial process is where true collaborative voices are truly realized and media-based community engagement comes alive. It is the editorial control given to the people you are working with that empowers their voices as experts in the community and creators of its representation.

\section{Methodology V: Walking and Applying Knowledge}

The izi.TRAVEL platform allows users to test their app tour before publishing it to the platform for the general public. This iteration is where the collaborative creative process is realized and excitement builds. Our young collaborators lead the way once more on the walking tour but this 
time with a smartphone in hand and earbuds in their ears listening to their voices and viewing the media they have created as they are geolocated on the route. The initial prototype walk-through also provides another layer of editorial control as we test out whether certain media are ordered correctly and the zones of geolocation are pinned correctly on the izi.travel platform.

After completing the walk-through, we have a debrief about the process, what worked and didn't work, discuss possible reordering of sites and possible changes. As anthropologists, this debrief provides another capacity for ethnographic data collection due to its format as a semi-structured interview which becomes valuable for reflection.

In this case, we were able to ascertain even more insight into the feelings our young collaborators had about their neighborhood changing and their concerns about losing things valuable to them. We see many possibilities for community engagement methodologies and data collection at this stage. Questions are asked once more about why particular sites are important and what meaning they have for our partners, both foundational ethnographic data points.

\section{Methodology VI: Going Live}

Once the group has agreed that the tour is set, the button is pushed and the tour is made live. This is an exciting moment, particularly for our youthful partners to see it come to life not only on a computer and smartphone, but now in the public sphere. Just as with the photovoice methodology, opportunities now exist to take friends, family members and others on the walking tour placing educational power with the children.

Feedback can be solicited by those taken along on the tour which becomes another valuable component of data expanding the local knowledge of sites for researchers. And participant observation can be undertaken as well providing yet another set of fieldnotes for ethnographic assessment and possible inclusion in the mobile app walking tour.

\section{Methodology VII: Assessment}

Effective community engagement is only as strong as the capacity to assess its impact. While this particular community engagement project is in its nascent stages, past utilization of this methodology has proven quite effective. For instance, we utilized the same process with partners from East Wilmington, DE, and the National Park Service (NPS) in 2018. Community members reported back in follow up conversations that while the app and walking tour was a positive outcome, it was the opportunity to build rapport with individuals they would normally not be able to talk about during the planning process that was the most meaningful. In addition, the NPS has utilized and replicated the model as a community engagement tool as they develop sites in Delaware. In addition, we have utilized the walking tour development project with students at Towson University in partnership with a variety of other communities including one in South Baltimore. This multi-year community collaboration with a fellow anthropologist in our department has provided both quantitative data of usage by high school students and anecdotal qualitative data. Quotes from students demonstrate that they appreciate the chance to develop technology tools and possess the authority to represent their lives and community. Finally, a walking tour developed with community members in the Baltimore neighborhood of Sharp Leadenhall illustrates how a walking tour can be utilized as a template for individuals becoming docents for walking tours themselves. Rough drafts can become fully developed web-based tours and resources as seen at the website https://sharpleadenhallwt.tumblr.com/ where a rich multimedia tour was created.

We look to the literature on community engagement once more to utilize another assessment tool. Distilio et al. (2012) provide a framework for gauging the nature of participatory community engagement through a three-step analysis of exchange, influence and generativity: 


\section{Figure 8}

Our collaborators and co-authors.

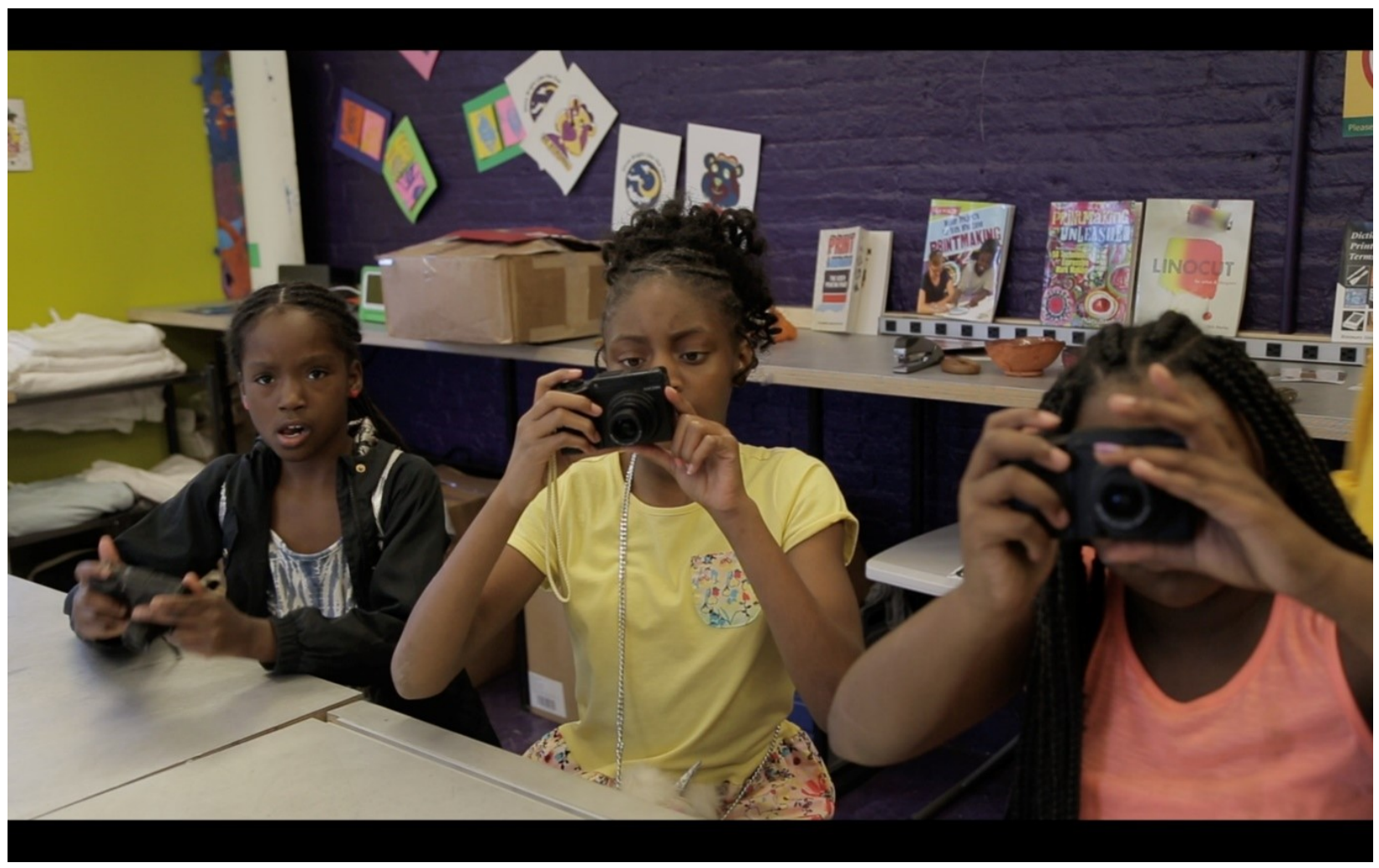

Exchange: Participants give and receive something from the others that they would not otherwise have. In this orientation, reciprocity is the interchange of benefits, resources, or actions...

Influence: The processes and/or outcomes of the collaboration are iteratively changed as a result of being influenced by the participants and their contributed ways of knowing and doing. In this orientation, reciprocity is expressed as a relational connection that is informed by personal, social, and environmental contexts...

Generativity: As a function of the collaborative relationship, participants (who have or develop identities as cocreators) become and/or produce something new together that would not otherwise exist. This orientation may involve transformation of individual ways of knowing and being or of the systems of which the relationship is a part. The collaboration may extend beyond the initial focus as outcomes, as ways of knowing, and as systems of belonging evolve. (Distilio et al., 2012, p. 19-20)

With this matrix in mind, this project in Greenmount West meets each of these community engagement criteria. There is demonstrated exchange through rapport building and collaborative exercises in developing the walking tour. Influence is demonstrated by having our young collaborators take the lead in developing the app, flipping the often-hierarchical nature of the research process. Finally, generativity is demonstrated in the outcome of the app being developed and a different way of seeing and knowing about the community through the lens of younger inhabitants. 


\section{FINDINGS}

The ethnographically informed mobile app walking tour project described in this article has findings typical to the nascent stages of long-term anthropological research that are valuable to cultural anthropologists but could be even more valued by community engagement practitioners.

1) When attempting to do any type of community engagement research that is ethnographically informed, the voice of your collaborators should guide the process as we have described.

2) When introducing novel technologies such as mobile app projects to community collaborators, a methodical process should be followed while ensuring that it is not deterministic. The insight of collaborators could and should change the course of the project.

3) While we may have an academic understanding of processes like gentrification, adding voices of those that are not often listened to such as youth, is an important indicator of what is occurring to all members of a community. Youth are just as anxious about being displaced as adults may be and their focus may be different than adults, and may be the safe spaces and friends that they rely upon on a daily basis.

4) By showing what youth value in a community, we are able to understand differential appreciation attached to space and place. While the neighborhood corner store may just be a place to get a snack or drink for an adult and perhaps not regarded as important on a walking tour, for a young person it may be the center of their cultural universe.

5) And, for those who both discount and underestimate the voice and technological savvy of youth in urban environments, you are missing an important ethnographic data set for understanding communities and their residents.

\section{CONCLUSION}

Although this exercise is specific to Baltimore's tumultuous urban development, this kind of collaborative work can be used in any community, and it underscores basic truths about the ways that urban-based research should be conducted. Researchers and university administrators can also highlight and replicate these novel experiments to demonstrate yet another tool for community engagement based in reciprocity. Translating this work to the public and our collaborators enhances participatory opportunities. This addresses an invitation by Hammersley for the "...higher education community to deconstruct key terms used to describe community engagement activities and relationships, and encourage critical reflection on our attempts to enact them through our research and practice" (Hammersley, 2017).

Fundamentally, community engagement work and research must always start with the perspectives of the local populations we interact with. And, simultaneously, there should be an ethical concern to create a constant mechanism for feedback and involvement. Hence, we do not adhere to the hierarchical authorship of the academics being the sole authors but positioning our interlocutors in the same space. It also asks that researchers work with communities towards forms of dissemination that are meaningful to people living in those communities. Furthermore, it outlines a collaborative process that works to break down hierarchies by engaging community members as experts rather than the subjects of research. It is just one example of the methodological toolkit for a Networked Anthropology.

Theorizing about the experience of walking in the city, Michel de Certeau wrote,

The long poem of walking manipulates spatial organizations, no matter how panoptic they may be: it is neither foreign 
to them (it can take place only within them) nor in conformity with them (it does not receive its identity from them). It creates shadows and ambiguities within them. It inserts its multitudinous references and citations into them (social models, cultural mores, personal factors). (de Certeau, 1984, p. 101)

Of course, walking around the neighborhood is no panacea to the many problems that may bedevil a community. It will probably not address questions of segregation, redlining, disinvestment, gentrification and abandonment. But as a form of collaboration, walking around a community guided by a community member's vision may work to critique neoliberal understandings, where people "deserve" what they get and the only way to create a healthy neighborhood is to land a Starbucks and a Whole Foods franchise, the oftentell-tale warnings of eventual class and racial displacement.
In this context, walking creates a space for critique in the ideological overdetermination of urban development in the U.S. For people in a community, the app may have similarly ambiguous outcomes. Will this really help stop the skyrocketing rents? Will it keep schools from being replaced by dubious charters? Whatever else, the collaborative app is another technology of place and place-making, inscribing a visible record of neighborhood identity. It provides a platform for further conversations and participatory research. The data gathered together -- the maps, photographs, recordings, films and texts -- are, ultimately, data for the community, to be re-mixed and re-used for presentations, grant applications and exhibits. In a larger media-based community engagement practice this is just one tool, but it provides demonstrable participatory opportunities. And, what we learned from this particular project is the power of the perspective of our young collaborators and co-authors. 


\section{REFERENCES}

Collins, S. G., \& Durington, M. (2015). Networked Anthropology. Routledge.

Collins, S. G., Durington, M., Favero, P., Harper, K., Kenner, A., \& O’Donnell, C. (2017). Ethnographic Apps/ Apps as Ethnography. Anthropology Now 9(1): 102-118.

Durington, M., Maddox, C., Ruhf, A., Gass, S., \& Schwermer, J. (2009). Civic Engagement and Gentrification Issues in Metropolitan Baltimore. Metropolitan Universities Journal (20)1: 101-114.

De Certeau, M. (2011). The Practice of Everyday Life. University of California Press.

Dostilio, L. D., et al. (2012). Reciprocity: saying what we mean and meaning what we say. Michigan Journal of Community Service Learning, 19(1) 2012, p. 17+.

Durington, M., \& Collins, S.G. (2016). Games without frontiers. In Gubrium, A., Editor, Harper, K., Editor \& Otanez, M. Editor (Eds.) Participatory Visual and Digital Research in Action (pp. 259-276) Left Coast Press.

Gubrium, A. \& Harper, K. (2013). Participatory Visual and Digital Methods. Routledge.

Hammersley L. (2017). Language Matters: Reciprocity and Its Multiple Meanings. In: Sachs, J. Editor \& Clark, L. (eds) Learning Through Community Engagement. (pp. 115-131). Springer.

Hjorth, L. (2014). Locating the social and mobile. Asiascape 1(1-2) 39-53.

Kenner, A. (2016). Asthma on the move. Health, Risk \& Society 17(7-8) 510-529.

Pink, S. (2009). Doing Sensory Ethnography. Sage.

Stocking, G. (1992). The Ethnographer's Magic and Other Essays in the History of Anthropology. Madison. University of Wisconsin Press. 